\title{
Lyapunov Üstelleri İle İris Örüntüsünün Kaotik Yapısının İncelenmesi
}

\author{
Hüsniye Kevser BAYRAKTAR ${ }^{1} \mathscr{\&}$, Özlem MUTLU ${ }^{1}$, Osman Hilmi KOÇAL ${ }^{1}$ \\ ${ }^{1}$ Bilgisayar Mühendisliği, Mühendislik Fakültesi, Yalova Üniversitesi, Yalova \\ $\bowtie$ : h.bayraktar@ogrenci.yalova.edu.tr
}

Geliş (Received): 15.03.2017

Düzeltme (Revision):11.05.2017

Kabul (Accepted): 18.05.2017

\section{ÖZ}

Kaos teorisi dinamik sistemleri, karmaşık ve doğrusal olmayan yapıları inceler. Doğada bulunan nesnelleri tanımlamak ve sınıflandırmak mühendislik disiplininin de ilgilendiği konulardır. Bu çalışmada biyometrik sistemlerde kullanılan iris dokusunun kaotik yapısı incelenmiştir. İris örüntüsü farklı bir bakış açısı ile ele alınmış ve irisin periyodiğimsi (pseudo-periodic) yörüngelerindeki kaotik yapı ortaya çıkarılmıştır. Uygulamada iris desenleri için UBIRIS veritabanı kullanılmıştır. İris görüntüsünden elde edilen tek boyutlu dizinin görsel analizi için veriler faz uzayına aktarılmış ve kaotikliği incelemek amacıyla Lyapunov üstelleri, TISEAN paket yazılımı aracılığıyla MATLAB ortamında hesaplanmıştır. Elde edilen sonuçlar irisin kaotik bir yapıya sahip olduğunu göstermektedir. Anahtar Kelimeler: Kaos, kaotik analiz, iris, lyapunov üstelleri, faz uzayı

\section{Investigation Of Chaotic Structure Of Iris Pattern By Using Lyapunov Exponents}

\begin{abstract}
Chaos theory examines dynamic systems, complex and nonlineer structures. Defining and classifying objects in the nature are also topics of interest to engineering discipline. In this study, the chaotic structure of iris tissue, which is used extensively in biometric systems, has been investigated. Iris pattern was handled from a different point of view and the chaotic structure in the pseudo-periodic orbits of iris was uncovered. In this research, UBIRIS database is used for iris patterns. The one dimensional array, obtained from the iris image, was transferred to the phase space to visual analysis and Lyapunov exponents were calculated in the MATLAB environment via TISEAN package software to investigate the chaotic behavior. The results show that iris has a chaotic structure.
\end{abstract}

Keywords: Chaos, chaotic analysis, iris, lyapunov exponent, phases pace

\section{GİRIŞ}

Kaos teorisinin mühendislik, sosyoloji, meteoroloji, tıp ve ekonomi gibi farklı disiplinlerde uygulama alanı bulunmaktadır. Zaman serilerinin analizi, geleceğe dair tahminler, görüntü ve ses verilerinin şifrelenmesi bunlardan bazılarıdır. Özelikle biyolojik sistemler karmaşık yapıları nedeniyle, kaos teorisinin en iyi uygulanma alanlarından biridir [1]. Kaos, karmaşadüzensizlik kavramıla ilişkilendirilmesine rağmen aralarında anlam farklılığı bulunmaktadır. Kaos, başlangıç koşullarına duyarlı, gürültü benzeri periyodik olmayan, periyodiğimsi (pseudo-periodic) olaylar, düzensizliğin düzeni şeklinde tanımlanabilir. Başlangıç koşullarına olan bağımlılık ve deterministlik kaosun en belirgin özellikleridir [2].

Göz irisi ile ilgili çalışmalar 1936 da başlamıştır. Göz doktoru olan Frank Burch [3] insanları tanımada iris deseninin kullanılabileceği düşüncesini ortaya atmıştır. Dr. Leonard Flom ve Dr. Aran Safir ise insanların irislerinin benzer olmadığını göstermişlerdir. İris tanımada yüz ve parmak tanımada olduğu gibi özel noktaların çıkarılması değil, doku arama ön plandadır. Biyometrik tanımada kullanılan bu dokular bireyden bireye, aynı zamanda sol ve sağ gözler için de birbirinden farklılık gösterir. Ayrıca iris deseninin doğumdan ölüme kadar dışarıdan bir etki olmadığ sürece değişmemesi tanıma sistemlerine büyük avantajlar sağlamaktadır [4].

$\mathrm{Bu}$ çalışmada daha önce üzerinde çalışılmamış olan tanıma sistemlerinde son derece avantajlı olan iris deseninde kaotik bir yapının olup olmadığ incelenmiştir. İkinci bölümde kaotikliği incelenecek olan iris verisinin nasıl elde edildiği anlatılmıştır. Kaotik yapının tespitinde kullanılan faz uzayı, Lyapunov üstellerinin tanımı ve nasıl kullanıldığı açıklanmıştır. Üçüncü bölümde deneysel sonuçlara yer verilmiştir. Son bölümde yapılan çalışmalar değerlendirilerek, kaotik analizin iris görüntülerinde ne amaçla kullanılabileceği üzerinde görüş bildirilmiştir.

\section{MATERYAL ve YÖNTEM}

Kaotik analiz yöntemleri zaman serileri üzerinden hesaplanan parametreleri kullanırlar. Kaotik analiz için kullanılan birçok yöntem bulunmaktadır. En yaygın olarak kullanılanlar: Poincare Haritalama, Güç Spektrumları, Lyapunov Üstelleri ve Fraktal Boyut 
Analizi'dir [5, 6]. Bu çalışmada iris verilerini analiz ederken Lyapunov üstelleri kullanılmıştır.

\section{Göz Resminden İris Bölgesinin Çıkarılması}

Çalı̧̧mada kaotikliği incelenecek olan göz resimleri UBIRIS [7] iris veri tabanından alınmıștır. Bu veri tabanının genel özellikleri; toplamda 241 kişiye ait 1877 görüntüden oluşur. Görüntüler 24 bit $800 \times 600$ piksel çözünürlüğünde, JPEG formatında olup Nikon E5700 kamera ile kayıt edilmiştir. Veri tabanı iki gruba ayrılmıştır. İlk guruptaki resimlerde gürültü miktarı az olup ikinci guruba göre daha kaliteli olduğu için çalışmada bu veriler kullanılmış ve her bir gözden bir adet görüntü seçilmiştir. İrisin kaotik yapısını incelemede ilk adım göz resminden iris bölgesinin bulunmasıdır. Bunun için göz bebeğinin siyah renginden yararlanılıp histogram kullanılarak bu bölge çıarılır.

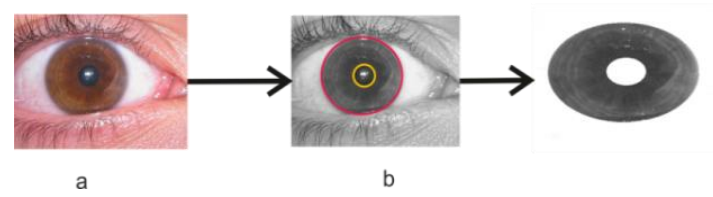

Şekil1. Göz imgesi, iris bölgesinin sınırları

İkinci adımda göz bebeğinin merkez noktası bulunur. Denklem (1) yardımıyla, bu merkez kullanılarak, $\mathrm{R}+(\mathrm{n} * \mathrm{r})$ şeklinde artan yarıçaplarda çemberler belirlenir. Burada R gözbebeğinin yarıçapı, $\mathrm{n}=1,2, .$. şeklinde artan bir tam sayı, $r$ ise çemberler arasındaki uzaklığı tanımlayan bir sabittir. En içte bulunan çemberden sıralı şekilde alınan pikseller bir dizi halinde sıralanır. Ardından, bir sonraki çemberdeki pikseller bir önceki çemberden elde edilen dizinin devamına eklenir. $\mathrm{Bu}$ şekilde irisin tamamındaki dairesel pikseller tek-boyutlu bir dizi olarak elde edilir (Şekil.2).

$r=\sqrt{x^{2}+y^{2}}$

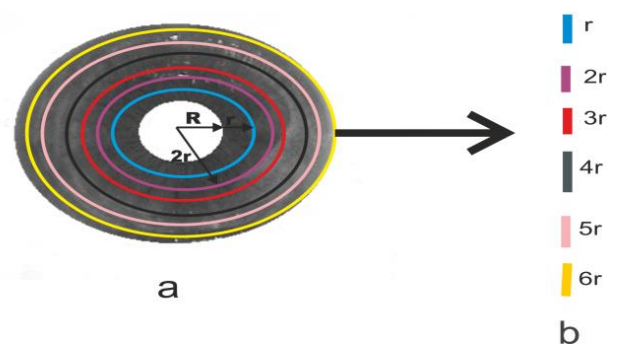

Şekil2.(a)İris üzerindeki çemberler, (b)iriste oluşturulan çemberlerin vektör halinde dizilmesi

Bir iris görüntüsünden elde edilen dizinin grafiği Şekil 3 'te çizdirilmiştir. Şekilde, yatay eksen verinin indeksini dikey eksen ise görüntüden alınan pikselin yoğunluk değerini göstermektedir.

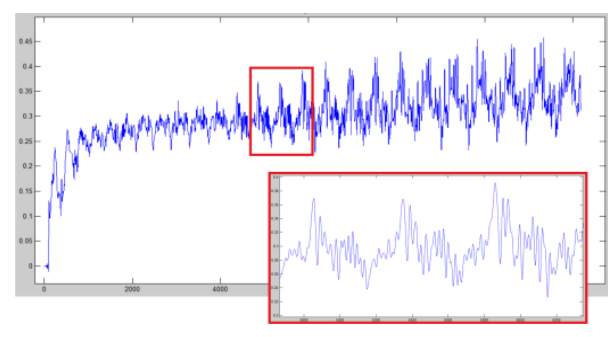

Şekil3. İristen alınan dairesel verilerin tek boyutlu vektörü

\section{Faz Uzayının Elde Edilmesi}

Faz uzay1, sistemi ifade eden parametrelerin grafikte tek bir noktada gösterilmesidir. Faz uzayının boyutu ise parametrelerin sayısıdır. Zaman serilerinde ise faz uzayı, verilerin zaman gecikmesi ile elde edilen kopyalarının birbirine göre davranışını gösteren diyagramdır. Bu çalı̧̧mada iristeki piksellerin birbiri arasındaki ilişkiyi ve kaotik yapıyı açıklamak için, iristen elde edilen vektörler zaman serisi gibi ele alınarak faz uzayına dönüştürülmüştür. Faz uzayı vektörleri denklem (2) yardımıyla eşitlik (4)'teki gibi oluşturulur. Matristeki her bir satır faz uzayındaki bir noktayı ifade eder [8].

$$
X(n)=\{x(n), x(n+L), \ldots \ldots \ldots x(n+(M-1) L)\}
$$

$$
x=\left\{x_{n}, n=1 \ldots . N\right\}
$$

$$
X(n)=\left[\begin{array}{cccc}
x_{1+(M-1) L} & . . & x_{1+L} & x_{1} \\
x_{2+(M-2) L} & . . & x_{2+L} & x_{2} \\
\cdot & \cdot & \cdot & \cdot \\
\cdot & . & \cdot & \cdot \\
x_{N} & . . & x_{N-(b-2) L} & x_{N-(b-1) L}
\end{array}\right]
$$

$\mathbf{x}(\mathbf{n})$ : serinin n'nci örneğidir.

L: zaman gecikmesidir. Her bir vektörün komșu elemanları arasındaki sabit zaman farkını belirtir. Zaman gecikmesi çok küçük olursa, her bir veri kendinden önceki veriye çok yakın olacak ve sinyalin faz uzayı geometrisi bozulacaktır. Zaman gecikmesinin çok büyük olduğu durumda ise birbirinden uzak veriler tamamen ilişkisiz olacağı için faz uzayı geometrisinde saçılma meydana gelecektir. Yukarıdaki tanımlar zaman serileri için geçerlidir. Bu çalışmadaki faz uzayı vektörlerinin elemanları zaman serisinden değil, iris çevresindeki farklı yarıçaplı çemberlerin üstündeki komşu piksellerden oluşmaktadır.

M: gömme (yerleştirme) boyutudur. Sistem dinamiklerini doğru analiz edebilmek için gömme boyutunun yeteri kadar yüksek seçilmesi gerekir. Genelde bu boyut en yakın komşuluk yöntemi 
kullanılarak hesaplanır [9, 10] Oluşturulan faz uzayı üzerinden Lyapunov üstelleri hesaplanır. Lyapunov üstelleri kullanılarak serinin kaotik olup olmadığına karar verilir.

\section{Lyapunov Üstelleri}

Bir sinyalin faz uzayı boyunca takip ettiği yol yörünge olarak adlandırılır. Lyapunov üsteli, komşu yörüngelerin birbirlerinden ayrılma miktarının niceliksel ölçütüdür[6-11,12]. Wolf tarafindan Lyapunov üstellerine bakılarak sistemin kaotikliğinin değerlendirmesi yapılmıştır. Faz uzayının farklı yönelimleri için ayrılma miktarı farklılık göstermektedir. Neticede, faz uzayının boyutu miktarınca Lyapunov üstelinden oluşan bir spektrum elde edilir. Pozitif bir üstel başlangıçta birbirine yakın olan yörüngelerin zamanla uzaklaştığı anlamına gelir ayrıca pozitif üstelin büyüklüğü yörüngelerin ne kadar hızlı oranda birbirlerinden uzaklaştığını belirtir. Benzer şekilde üstelin negatif olması da yörüngelerin birbirlerine zamanla yaklaştı̆̆ı anlamına gelir. Üstel değerlerinin büyük olması sistemin daha fazla tahmin edilemez olduğunu gösterir.

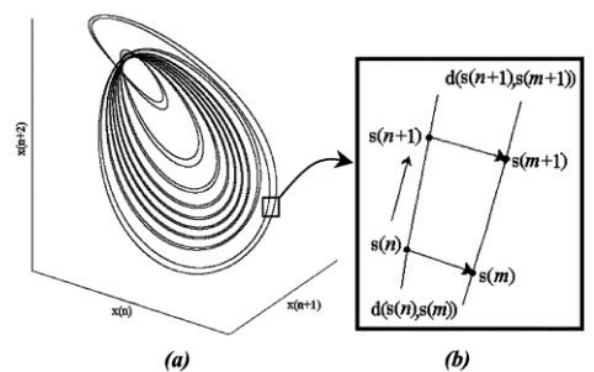

Şekil4. Lyapunov üstellerinin hesaplanması ((a) faz uzayı,(b) komşu iki yörünge) [12]

Denklem (5)'de, s(n) referans noktas1, ona en yakın komşu $\mathrm{s}(\mathrm{m})$ ve $d(s(n), s(m))$ başlangıçtaki en yakın komşular arasındaki uzaklıktır. Sonraki iki nokta arasındaki Öklid uzaklığı $d(s(n+1), s(m+1))$

olmak üzere her bir nokta için bu Öklid uzaklığı $\mathrm{N}$ defa tekrarlanarak Lyapunov üstelleri hesaplanıp üstellerin ortalaması alınarak yörüngelerdeki yakınlaşma ve uzaklaşmayı ifade eden $\lambda$, denklem (5) ile elde edilir.

$\lambda=\frac{1}{N} \sum_{t=1}^{N} \ln \frac{d(s(n+1), s(m+1))}{d(s(n), s(m))}$

Faz uzayındaki boyut sayısınca Lyapunov üstelinin her biri $\quad\left\{\lambda_{1}, \lambda_{2}, \ldots, \lambda_{M}\right\} \quad$ eşitlik (5) kullanılarak hesaplanır. $\lambda_{1}$ pozitif en büyük değerdir ve verinin kaotik yapıda olduğunu gösterir [12-14, 15].

\section{BULGULAR ve TARTIŞMA}

UBIRIS veri tabanından alınan göz resimlerinden iris bölgesini çıkarma işlemi MATLAB programlama dili ile yapılmıştır. İris vektörünün kaotik davranışını görmek için bu veriler faz uzayına taşınmış ve Şekil 5 'te iki boyutlu çizdirilmiştir. Bunun için iristen elde edilen veri üzerinde zaman gecikmesi üç alınarak verinin zaman gecikmeli bir kopyası elde edilmiştir. Yatay ve dikey eksene asıl veri ve zaman gecikmeli veri yerleştirilmiştir. Bu şekilde, asıl vektördeki bir nokta belirlenen zaman gecikmesi sonrasındaki başka bir noktaya karşılık olarak çizdirilmiştir.

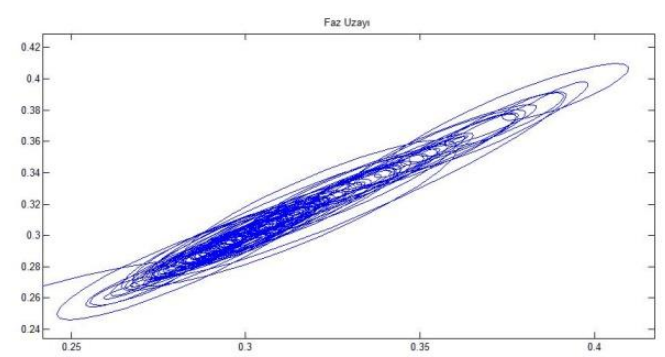

Şekil .5. İrisin faz uzayındaki kaotik yapısı

Periyodik olmayan ve sonsuza genişlemeyen faz-uzayı kaotikliğin bir göstergesidir. $\mathrm{Bu}$ nedenle Şekil 5'te kaotik yap1 görülmektedir. $\mathrm{Bu}$ faz uzayının üzerinde metot kısmında bahsedilen denklem (5) kullanılarak Lyapunov üstelleri hesaplanmıştır.

İris yapısının kaotik olup olmadığının nicel olarak anlaşılması için açık kaynak kodlu TISEAN(Time Series Analysis) 3.0.0. paketinde bulunan lyap_spec fonksiyonu kullanılmış ve elde edilen sonuçlardan bazıları Tablo 1'de verilmiştir.

Tablo 1. İris dokusunun Lyapunov üstelleri

\begin{tabular}{|c|c|c|c|c|}
\hline & $\begin{array}{l}\text { Lyapunov } \\
\text { Üsteli } \\
1 \\
\end{array}$ & $\begin{array}{l}\text { Lyapunov } \\
\text { Üsteli } \\
2 \\
\end{array}$ & $\begin{array}{l}\text { Lyapunov } \\
\text { Üsteli } \\
\mathbf{3} \\
\end{array}$ & $\begin{array}{l}\text { Kaos } \\
\text { Analiz }\end{array}$ \\
\hline 1 & $\begin{array}{l}6.129047 \\
\text { e-002 }\end{array}$ & $\begin{array}{l}-2.181212 \\
\text { e-003 }\end{array}$ & $\begin{array}{l}-7.072407 \\
\text { e-002 }\end{array}$ & Kaotiktir \\
\hline 2 & $\begin{array}{l}4.499470 \\
\text { e- } 002\end{array}$ & $\begin{array}{l}-6.490098 \\
e-003\end{array}$ & $\begin{array}{l}-4.931766 \\
\text { e- } 002\end{array}$ & Kaotiktir \\
\hline 3 & $\begin{array}{l}3.636041 \\
\mathrm{e}-002\end{array}$ & $\begin{array}{l}3.421851 \\
\mathrm{e}-003\end{array}$ & $\begin{array}{l}-5.100879 \\
\mathrm{e}-002\end{array}$ & Kaotiktir \\
\hline 4 & $\begin{array}{l}4.731833 \\
\text { e- } 002\end{array}$ & $\begin{array}{l}-3.758361 \\
\mathrm{e}-003\end{array}$ & $\begin{array}{l}-5.637153 \\
\mathrm{e}-002\end{array}$ & Kaotiktir \\
\hline
\end{tabular}

Gömme boyutu üç alındığı için tabloda gömme boyutu kadar Lyapunov üsteli vardır. Verilerin kaotik durum göstermesi için Lyapunov üstellerinden en az bir tanesinin pozitif bir değerde olması gerekir. Veri tabanındaki tüm iris vektörlerinden elde edilen Lyapunov üstellerinden en az bir tanesi pozitif çıkmıştır. $\mathrm{Bu}$ irislerden elde edilen sonuçlardan birkaçı Tablo 1'de örnek olarak gösterilmiştir. $\mathrm{Bu}$ sonuç, tüm veri 
tabanındaki iris dokusunun kaotik olduğunu göstermektedir.

\section{SONUÇ}

Biyometride son derece popüler olan iris dokusunda kaotik bir yapının var olup olmadığını görsel ve nicel olarak incelemek amaciyla UBIRIS veri tabanında tüm gözler üzerinde çeşitli yöntemler ve deneyler kullanıldı. Göz resminden iris dokusu bölüm ikide belirtildiği gibi bir vektör şeklinde çıkarıldı. Öncelikle iris dokusunun kaotik davranış gösterip göstermediğini zaman boyutunda görsel olarak görmek için veriler faz uzayına aktarıldı. Faz uzayı pseudo-periyodik kapalı bir eğri olup Şekil 5'te görüldüğü gibi kaotik bir yap1 göstermektedir. İkinci aşamada nicel olarak kaotikliğini ispat etmek için Lyapunov üstelleri kullanıldı. Çıkan sonuçlar incelendiğinde tüm iris görüntülerinin Tablo 1'de görüldüğü gibi kaotik yapıya sahip olduğu görülmektedir. Yani tüm veriler için en az bir adet pozitif üstel bulunmaktadır.

Uygulamalı bilimler, tanımlayıcı bilimlerin sağladığı bilgi tabanını kullanarak doğayı ve sistemleri belirli hedeflere yönlendirecek çalışmaları yapmayı amaçlar. $\mathrm{Bu}$ amaç doğrultusunda irisin kaotik yapısının ortaya çıkarılması ileriki çalışmaların alt yapısı olarak kullanılabilir.

İrisin kaotik özelliğindeki zayıflama, Lypunov üstellerinin yakınlaşması, Lypunov spektrumunun daralması, doğal yapının bozulması hastalık işaretçisi olabilir. Bu durum, sağlıklı göz ile hastalıklı göz sınıflandırılmasında kullanılabilir. İrisin Lyapunov üstelleri, sınıflandırma amaçlı öznitelik vektörü elemanı olarak da düşünülebilir. İris deseninin kaotik yapısını çıkarmada, işlem zamanını azaltmak için daha yüksek performansla çalışmaya yönelik yeni algoritmalar ile iyileştirme yapılabilir.

\section{KAYNAKÇA}

[1] Yılmaz D., Güler N. F., Kaotik zaman serisinin analizi üzerine bir araştırma: Gazi Uni. Müh. Mim. Fak. Der. 21, 759-779, 2006.

[2] Ünal Ş., Kaos: Yeni Bir Paradigma Mi?, Felsefe ve Sosyal Bilimler Dergisi, 5, 101-114, 2007.

[3] Tisse C., Martin L., Torres L., Robert M. Person Identification Technique Using Human Iris Recognition, 15th International Conference on Vision Interface, 294299, 2002.

[4] Ahmet T., Faz Korelasyonu Temelli Gömülü İris Tanıma Sistemi, Kocaeli Üniversitesi Fen Bilimleri Enstitüsü, 2011.

[5] Nihat P. Dinamik Sistemlerde Kaotik Zaman Dizilerinin Tespiti: BAÜ Fen Bil. Ens. Dergisi, 15, 77-91, 2013.

[6] Özkaynak F. Doğrusal olmayan sistemlerde lyapunov üstellerinin hesaplayan yazılımın gerçekleştirilmesi: yüksek lisans tezi, 2007.

[7] htttp://iris.di.ubi.pt/, Erişim tarihi: Ocak 2017

[8] Aydın İ. Karaköse M., Akın E. Zaman Serileri Veri Madenciliği Tekniği Kullanılarak Asenkron Motorlarda Sarım Ve Sürtünme Hatalarının Teşhisi, Elektrik-
Elektronik-Bilgisayar Mühendisliği 11. Ulusal Kongresi ve Fuar1, 1, 223-226, 2005.

[9] Yılmaz D. Güler N. F. Kaotik Zaman Serisinin Analizi Üzerine Bir Araştırma, Gazi Üniversitesi Mühendislik Fakültesi Dergisi, 2006.

[10] Genç S. Proteinlerdeki düzensiz bölgelerin tespiti için kaotik ve fizikokimyasal özellikler tabanlı yeni öznitelik kodlama yöntemleri geliştirilmesi: Yüksek lisans tezi, 2015.

[11] Strogatz S. H. Nonlinear Dynamics and Chaos, Perseus Books Publishing, p. 498, 1994.

[12] Kocal O. H., Yürüklü E., Avcıbas İ. Chaotic-Type Features for Speech Steganalysis, IEEE Transactions on Information Forensics and Security, 3, 651-661, 2008.

[13] Wolf A., Swift J. B., Swinney H. L., Vastano J. A. Determining lyapunov exponents from time series, Physical Review D, 16, 285-317, 1985.

[14] Yardım F. E., Afacan E. Lorenz tabanlı diferansiyel kaos kaydırmalı anahtarlama (DCSK) modeli kullanılarak kaotik bir haberleşme sisteminin simülasyonu, Gazi Üniversitesi

[15] Sandri M. Numerical calculation of Lyapunov exponents, The Mathematical Journal, 6, 78-84, 1996. 